\title{
Pterional and Unifrontal Approaches for the Microsurgical Resection of Olfactory Groove Meningiomas: Experience with 61 Consecutive Patients
}

\author{
Mustafa GUDUK, Ulas YENER, Halil Ibrahim SUN, Mehmet HACIHANEFIOGLU, Koray OZDUMAN, \\ M. Necmettin PAMIR \\ Acibadem University, School of Medicine, Department of Neurosurgery, Istanbul, Turkey
}

\section{ABSTRACT}

AIM: Olfactory groove meningiomas make up 4 to $13 \%$ of meningiomas. The first line treatment of meningiomas is surgery, but the extent and types of approaches advised for olfactory groove meningiomas are diverse, from aggressive skull base approaches to standard or minimally invasive craniotomies and endoscopic approaches. We retrospectively reviewed our series of olfactory groove meningiomas that were operated microsurgically by standard pterional or unifrontal approaches.

MATERIAL and METHODS: Our series of 61 olfactory groove meningioma patients operated through pterional or unifrontal approaches between March 1987 and September 2015 was reviewed and the clinical data, radiological findings, surgical treatment and clinical outcomes of the patients were retrospectively analyzed.

RESULTS: Sixty-three craniotomies were performed in total. Pterional and unifrontal approaches were used in 38 (60.3\%) and 25 $(39.7 \%)$ surgical procedures, respectively. Overall, gross total tumor resection was achieved in 59 (93.7\%) cases. Complications were seen in 8 cases, and 2 of these patients underwent reoperation. Three of the 4 patients where only subtotal resection could be achieved underwent gamma knife radiosurgery.

CONCLUSION: Pterional and unifrontal approaches, which are familiar and standard for neurosurgeons, can accomplish high rates of total resection with acceptable complication and recurrence rates for the treatment of olfactory groove meningiomas.

KEYWORDS: Meningioma, Anterior fossa meningioma, Olfactory groove meningioma, Microsurgery

\section{INTRODUCTION}

$\mathrm{O}$ Ifactory groove meningiomas (OGMs) account for $4-13 \%$ of all intracranial meningiomas. They originate from the dura of the anterior cranial fossa over the cribriform plate and frontosphenoidal suture $(7,10,11,25,36)$.

OGMs usually present with hypo/anosmia, visual deterioration, mental changes and headache as a result of olfactory or optic nerve and frontal lobe compression. Seizures are also common in these patients $(8,33)$. However, these tumors grow slowly and usually remain clinically quiescent during the early phases of tumor growth leading to large tumor sizes at the time of diagnosis $(8,33,41)$. The differentiation from meningiomas of the planum sphenoidale and tuberculum sellae is of clinical and surgical importance; tumors arising from these sites are usually diagnosed at an early stage due to visual impairment, which is a late finding in OGMs $(7,11,22,28)$.

Anatomically, OGMs arise from the weakest part of the skull base, i.e. the cribriform plate, making them prone to infiltrate the underlying bone and extend into the paranasal sinuses and nasal cavity. This feature is rarely observed in planum 
sphenoidale and tuberculum sellae meningiomas $(7,28)$. In addition to the large size of the tumors at diagnosis and their invasion into paranasal sinuses, encasement of important vascular and neural structures raises major challenges during surgical procedures $(8,10,22,28)$.

Several surgical approaches have been used to remove OGMs, with the pterional and subfrontal (unifrontal or bifrontal) approaches being the most popular, but designating the optimal surgical approach is still controversial $(1,3,8,10,11,14,17,19,25,28,32-34,36,37)$.

We retrospectively analyzed our series of 61 patients with OGMs with regard to clinical presentation, tumor characteristics, surgical approaches and follow-up results after being operated microsurgically through a pterional or unifrontal craniotomy.

\section{MATERIAL and METHODS}

\section{Patient Population}

Between March 1987 and September 2015 we have operated on a total of 1261 cases of meningiomas, and of these 1261 patients $61(4.8 \%)$ had OGMs that were operated on

Table I: Distribution of Symptoms/Signs

\begin{tabular}{lc}
\hline Symptoms and signs & Number (\%) \\
\hline Headache & $26(42.6)$ \\
\hline Visual symptoms/signs & $22(36.1)$ \\
\hline Mental changes & $15(24.6)$ \\
\hline Anosmia/hyposmia & $15(24.6)$ \\
\hline Seizures & $10(16.4)$ \\
\hline Vertigo & $9(14.8)$ \\
\hline Nausea/vomiting & $6(9.8)$ \\
\hline Syncope & $3(4.9)$ \\
\hline Incidental & $2(3.3)$ \\
\hline Hemiparesis & $1(1.6)$ \\
\hline Menstrual problems & $1(1.6)$ \\
\hline
\end{tabular}

microsurgically. The medical charts, radiological studies, surgical and pathological records were retrospectively reviewed.

Of the 61 patients, 42 (68.9\%) were women and $19(31.1 \%)$ were men, with a median age of 58 years (range, 33-80 years). The preoperative median Karnofsky Performance Score (KPS) of the patients was 100 (range, 60-100). The median follow-up was 64 months (range, 1-239 months). The most frequent complaint was headache $(42.6 \%)$ followed by visual impairment $(36.1 \%)$, anosmia/hyposmia $(24.6 \%)$ and mental changes (24.6\%). In 2 patients (3.3\%), OGMs were encountered incidentally (Table I).

The tumor was diagnosed using magnetic resonance imaging (MRI) and/or computed tomography (CT) with and without contrast agent, the latter being the only radiological study in patients operated before 1992 (3 patients). None of the patients had cerebral digital subtraction angiography (DSA) for diagnostic or embolization purposes. Four (6.6\%) patients were previously operated at another institution due to OGM.

In the follow-up of patients along with clinical examination, $\mathrm{MRI}$ with and without contrast studies was performed at postoperative 24 hours, and 3 months after surgery. Based on the clinical and radiological findings, later follow-up was done once a year until the postoperative fifth year, and then every 2 years. Preoperative and postoperative MRIs of four demonstrative patients are presented in Figure $1 \mathrm{~A}-\mathrm{H}$.

\section{Tumor Size and Extension Patterns}

Patients were divided into 3 groups according to the largest diameter of the tumor; small $(\leq 3 \mathrm{~cm})$, medium $(3-6 \mathrm{~cm})$ and large $(\geq 6 \mathrm{~cm})$ OGMs. Overall the mean tumor size was $4.9 \mathrm{~cm}$ (range, $1.5-9 \mathrm{~cm}$ ). There were $11(18.0 \%)$ small, 30 medium $(49.2 \%)$ and 20 large (32.8\%) tumors in a total of 61 patients. Concerning the tumor extension, hyperostosis was present in 45 (73.8\%), ethmoidal invasion in 18 (29.5\%), middle fossa extension in 7 (11.5\%), optic canal involvement in 6 (9.8\%) and vascular encasement in $5(8.2 \%)$ patients. The presence of these five extension patterns was significantly related with the size of the tumor $(p<0.05)$, and optic canal involvement, vascular encasement and middle fossa extension were not seen in small OGMs. The extension patterns according to the tumor size are presented in Table II.

Table II: Extension Patterns of Tumors according to the Tumor Size in 61 Patients

\begin{tabular}{lccr}
\hline Tumor extension & $\begin{array}{c}\text { Small } \\
\text { No. of pts (\%) }\end{array}$ & $\begin{array}{c}\text { Medium } \\
\text { No. of pts (\%) }\end{array}$ & $\begin{array}{c}\text { Large } \\
\text { No. of pts (\%) }\end{array}$ \\
\hline Hyperostosis & $3(27.3)$ & $23(76.7)$ & $19(95.0)$ \\
Ethmoidal invasion & $3(27.3)$ & $9(30.0)$ & $6(30.0)$ \\
Middle fossa extension & $0(0)$ & $2(6.7)$ & $5(25.0)$ \\
Optic canal involvement & $0(0)$ & $2(6.7)$ & $4(20.0)$ \\
Vascular encasement & $0(0)$ & $2(6.7)$ & $3(15.0)$ \\
\hline No. of patients & 11 & 30 & 20 \\
\hline$\%$ & 18.0 & 49.2 & 32.8 \\
\hline
\end{tabular}



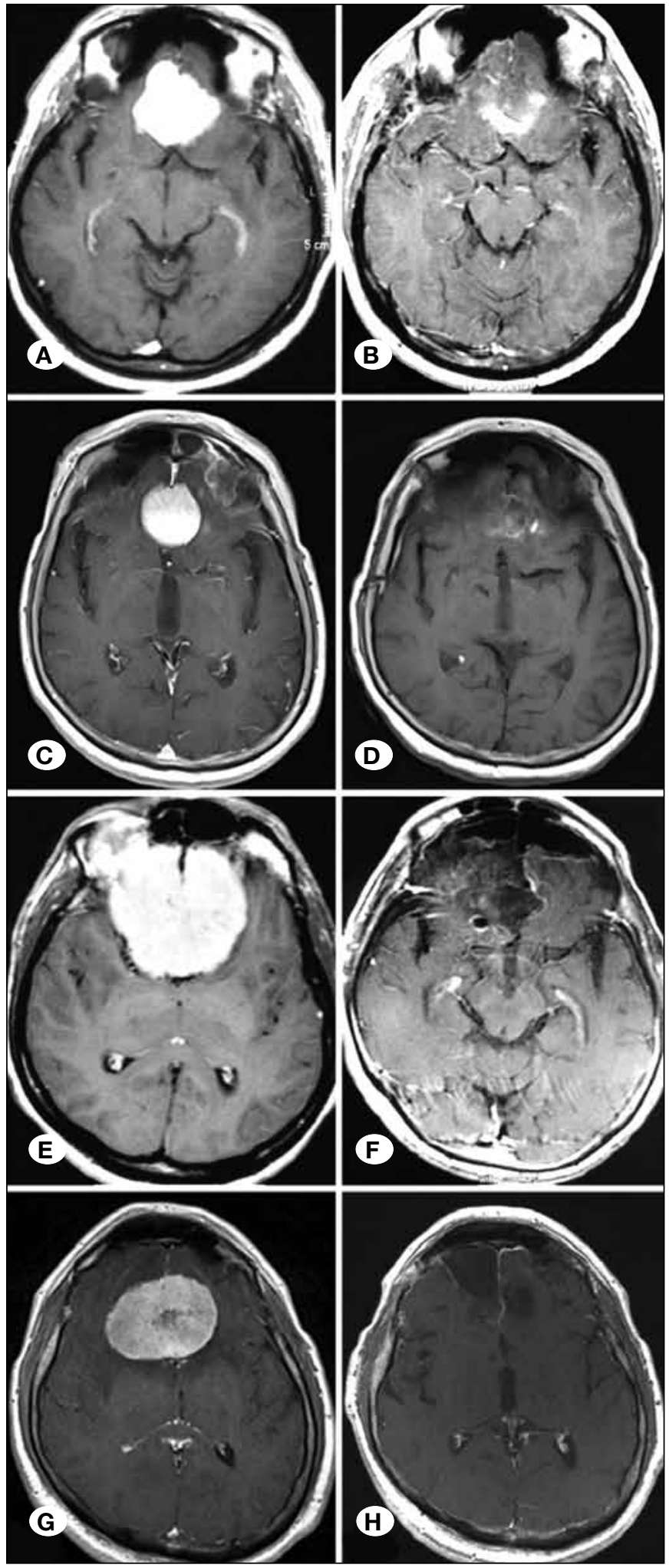

Figure 1: Four demonstrative cases are presented. Patients A) and C) were operated by the pterional approach, while patients E) and G) were operated through the unifrontal route. B), D), F) and $\mathbf{H}$ ) are their control MRIs, respectively.

\section{Surgical Approaches}

A total of 63 surgical procedures were performed using the pterional $(n=38,60.3 \%)$ and unifrontal $(n=25,39.7 \%)$ approaches.

The pterional approach was performed as described by Yaşargil (42). Classically, the lateral part of the frontal bone, the anterior part of the squamous part of the temporal bone, and the lateral part of the greater wing of the sphenoid bone is mobilized and removed in the pterional approach. We extended the frontal part of the bone flap medially and inferiorly to make it easier to reach and manipulate the anterior fossa from a wide angle. The intraoperative steps of this approach after the dural opening are shown in Figure $2 \mathrm{~A}-\mathrm{H}$.

We used unifrontal craniotomy for large tumors or tumors with ethmoidal invasion or optic canal involvement. In that fashion, we could see the tumor from the midline, bilaterally and could manipulate the inferior parts of the tumor. We performed a unifrontal approach using bifrontal skin incision, with a bone flap extending medially to the midsagittal line, and laterally to the anterior part of the greater wing of the sphenoid bone. We kept the galeal tissue as a vascular flap to use in case of cribriform drilling. We mobilized the bone flap anteriorly above the orbital roof and posteriorly we extended the craniotomy anterior to the coronal suture. In this fashion, we could work from a wide angle subfrontally and interhemispherically while we could keep the superior sagittal sinus intact, and manipulate the falx when necessary. We drilled the cribriform plate and excised the tumors extending to the ethmoid when needed and during closure, we packed the muscle tissue harvested from the lateral part of the leg of the patient to the ethmoid space and lay fascia lata autograft harvested from the same place. The galeal flap was placed over these and surgical glue was used as needed. Figure $3 \mathrm{~A}-\mathrm{H}$ presents the intraoperative details of unifrontal approach with photographs.

\section{Coincidental Intracranial Pathologies}

Three patients had coincidental pathologies; one 71-year-old female patient had a right frontal glioblastoma and another 57-year-old female patient had a right frontal convexity meningioma. Both of these pathologies were totally resected in the same session. One male patient who was 60 years old had a coincidental right middle cerebral artery (MCA) bifurcation aneurysm which was operated in the same session.

\section{Statistical Analysis}

Data were analyzed using the statistical software package SPSS 21.0 for Windows (SPSS Inc., Chicago, IL). Pearson's chi-squared test and Fisher exact test were used to compare categorical variables. Kaplan-Meier analysis was done to assess the effect of risk factors on recurrence-free survival (RFS). Cox regression for multivariate analysis of risk factors could not be performed due to the small size of the recurrence/ re-growth population. $\mathrm{p}<0.05$ was considered as statistically significant. 


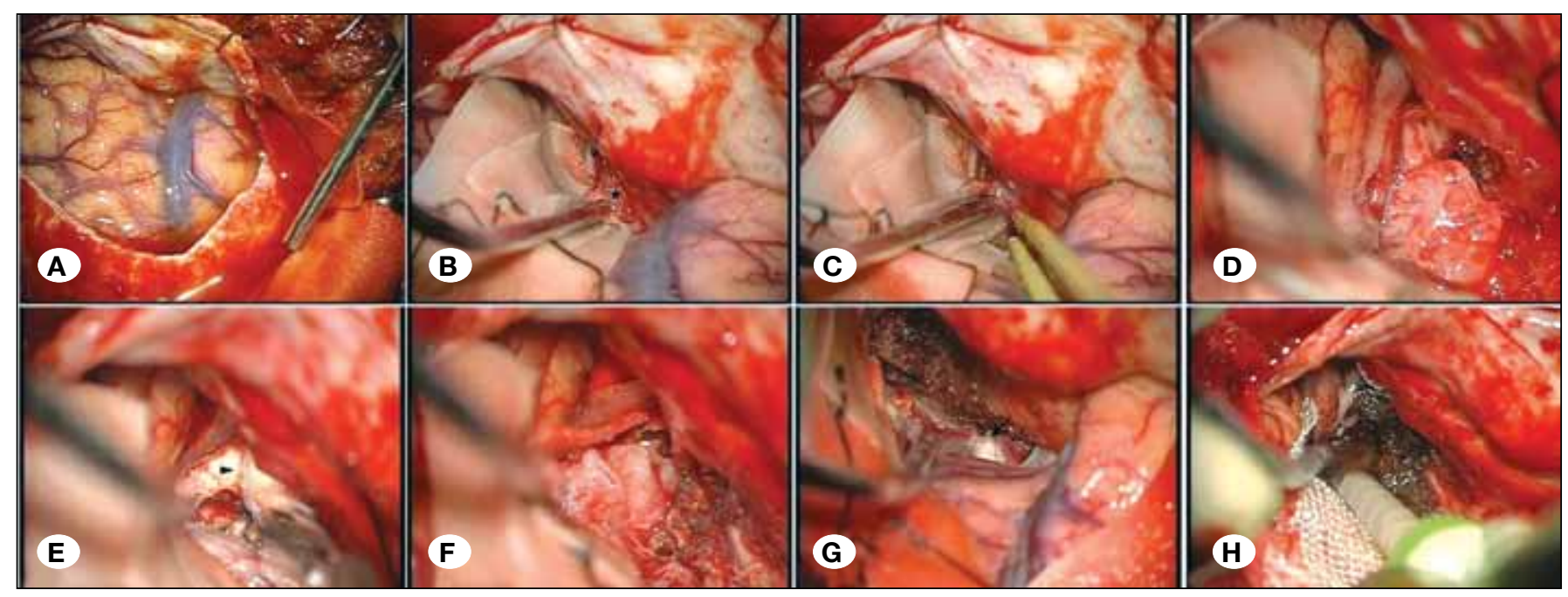

Figure 2: After pterional craniotomy, A) the dura is opened. B) The tumor (asterisk) and right olfactory nerve (pointed arrow) are seen. C) After devascularization and incision from the frontobasal dura, D) tumor excision begins. E) When we reach the falx (arrowhead), it is incised and F) the contralateral tumor is excised. G) The basal dura is cauterized and the right optic nerve is seen (black arrow). H) Surgical glue is used as needed.

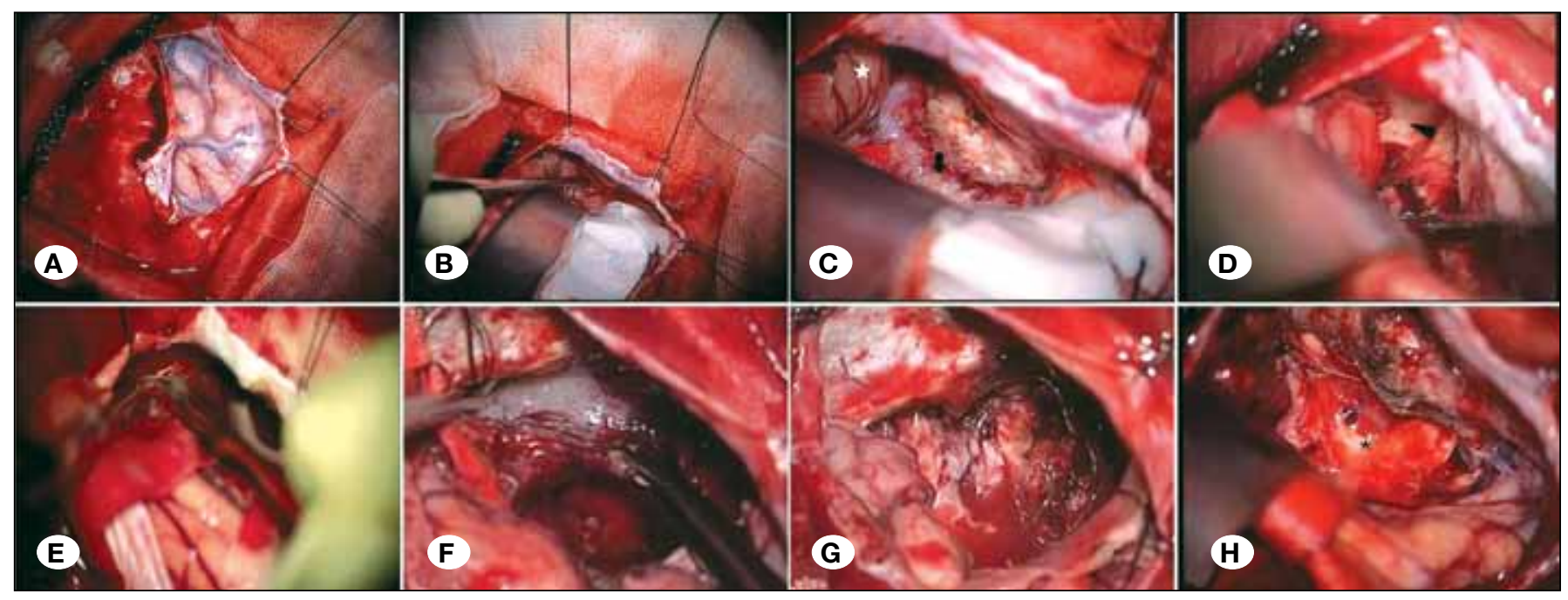

Figure 3: After unifrontal craniotomy reaching the subfrontal area and extending to the midline, the dura is opened (A), devascularization and excision of the tumor is begun (B). C) The brain (white star) and the tumor (black arrow) are seen. D) When the falx (arrowhead) is reached, it is incised $(\mathbf{E})$ and the contralateral tumor tissue is resected (F-H). The subfrontal area, optic nerves and chiasm (asterisk) are seen.

\section{- RESULTS}

\section{Surgical Approach and Tumor Size}

A total of 13 procedures were performed on small OGMs. The pterional approach was used in $10(76.9 \%)$ of cases, whereas $3(23.1 \%)$ tumors were resected through the unifrontal route (Table III). Among the 30 medium sized OGMs, 21 (70.0\%) were operated on via the pterional approach and 9 (30.0\%) via the unifrontal approach. Large OGMs $(n=20)$ were approached through the pterional route in 7 (35.0\%) and through the unifrontal route in $13(65.0 \%)$ cases. The pterional approach was used significantly more frequently in small and medium sized OGMs $(p<0.05)$.

\section{Surgical Approach and Extent of Tumor Resection}

Overall, gross total resection (GTR) was achieved in 59 $(93.7 \%)$ procedures, whereas tumor resection was assessed as subtotal in $4(6.3 \%)$ procedures. In 2 of the subtotally resected tumors, the anterior communicating artery complex was encased by the tumor, while in one tumor the recurrent artery of Heubner was encased and residual tumors were left. These three residual tumors underwent Gamma Knife radiosurgery and these residual tumors are still under control after a median follow-up of 74 months (range 52-86 months). The fourth subtotally resected tumor was previously operated at another center and although we performed ethmoidal drilling and resection, a residual tumor with a diameter of 5 
$\mathrm{mm}$ was observed at postoperative 24 hours control MRI. In the follow-up, re-growth was seen and the residual tumor was operated 2 years later by the pterional approach and GTR was achieved. We did not perform Gamma Knife radiosurgery for the residual tumor of this patient because she was operated before January 1997, the time Gamma Knife facility was available in our country.

GTR was possible in 38 pterional and 21 unifrontal approaches. Therefore, the pterional approach allowed a significantly greater percentage of GTR than the unifrontal approach $(p<0.05)$. In other words, the unifrontal approach was associated with a significantly higher number of patients with subtotal resection (STR) $(p<0.05)$. Table IV summarizes the extent of resection and the approaches used.

Ethmoidal invasion, middle fossa extension, optic canal involvement and vascular encasement were associated with a higher number of patients with STR $(p<0.05)$ while there was no association between the extent of resection and hyperostosis.

\section{Surgical Approach and Complications}

Postoperative complications were observed in 8 (12.7\%) out of 63 operations (Table V). Complications were seen in $3(7.9 \%)$ and $5(20.0 \%)$ patients operated via the pterional and unifrontal approach, respectively. The most frequent complications observed were hematoma $(n=2)$ and contusion $(n=2)$. Overall reoperation for complications was required in 2 cases (3.2\%; 1 hematoma evacuation, 1 ventriculoperitoneal shunting). There was no statistically significant correlation between surgical approach and the rate of complications.

The unifrontal approach resulted in a greater percentage of reoperations for complications compared to the pterional approach (pterional $n=0$, unifrontal $n=2$ ). Contusions were

Table III: Distribution of Surgical Approaches According to Tumor Diameter

\begin{tabular}{lcccc}
\hline Surgical approach & Small; $\mathbf{n}(\%)$ & Medium; $\mathbf{n}(\%)$ & Large; $\mathbf{n}(\%)$ & All cases*; $\mathbf{n ~ ( \% ) ~}$ \\
\hline Pterional & $10(76.9)$ & $21(70.0)$ & $7(35.0)$ & $38(60.3)$ \\
\hline Unifrontal & $3(23.1)$ & $9(30.0)$ & $13(65.0)$ & $25(39.7)$ \\
\hline Total & $13(100)$ & $30(100)$ & $20(100)$ & $63(100)$ \\
\hline
\end{tabular}

*2 patients were re-operated for recurrence/re-growth later.

Table IV: Surgical Approach and Extent of Tumor Resection

\begin{tabular}{lcccc}
\hline & Approach & GTR & STR & All cases* \\
\hline First operation; $\mathrm{n}(\%)$ & Pterional & $36(100)$ & $0(0)$ & $36(100)$ \\
\hline & Unifrontal & $21(84)$ & $4(16)$ & $25(100)$ \\
Second operation; $\mathrm{n}(\%)$ & Pterional & $2(100)$ & 0 & $2(100)$ \\
\cline { 2 - 5 } & Unifrontal & 0 & 0 & $0(100)$ \\
\hline All cases; $\mathrm{n}(\%)$ & & $59(93.7)$ & $4(6.3)$ & $63(100)$ \\
\hline
\end{tabular}

*2 patients were re-operated for recurrence/re-growth later. GTR: Gross total resection, STR: Subtotal resection.

Table V: Distribution of Complications and Deaths according to Surgical Approach

\begin{tabular}{|c|c|c|c|}
\hline Complications & Pterional; n=38 (\%) & Unifrontal; n=25 (\%) & All cases*; n=63 (\%) \\
\hline Hematoma & 0 & $2(8.0)$ & $2(3.2)$ \\
\hline Contusion & $2(5.3)$ & 0 & $2(3.2)$ \\
\hline CSF leak & 0 & $1(4.0)$ & $1(1.6)$ \\
\hline Wound infection & 0 & $1(4.0)$ & $1(1.6)$ \\
\hline Hydrocephalus & 0 & $1(4.0)$ & $1(1.6)$ \\
\hline Vascular infarction & $1(2.6)$ & 0 & $1(1.6)$ \\
\hline Total & $3(7.9)$ & $5(20.0)$ & $8(12.7)$ \\
\hline Deaths & $1(2.6)$ & 0 & $1(1.6)$ \\
\hline
\end{tabular}

*2 patients were re-operated for recurrence/re-growth later. CSF: cerebrospinal fluid. 
observed in the operation lodge in 2 patients who were treated by medical treatment. Cerebrospinal fluid (CSF) leak was observed in one patient operated via the frontal route and was treated successfully with lumbar drainage. Two patients experienced intracranial hematoma with resulting surgical evacuation in one patient. Hydrocephalus was diagnosed in one patient at 7 months and required a ventriculoperitoneal shunt operation. One patient who was operated by the unifrontal approach developed wound infection 15 months later, and was treated by antibiotherapy. One patient who was operated through a right pterional approach died postoperatively at day 9 due to left MCA infarction that occurred on postoperative day 7 although she had an uneventful postoperative period and was discharged on postoperative day 4 .

\section{Histological Grading of Tumors}

According to the World Health Organisation (WHO) classification, 59 tumors (93.7\%) were Grade 1 (40 meningothelial, 12 transitional, 2 secretory, 2 secretory/transitional, 1 fibroblastic, 1 meningothelial/psammomatous, 1 meningothelial/microcystic) and $4(6.3 \%)$ were grade 2 (4 atypical). Two of the grade 2 meningiomas were from the same patient who had a second operation for recurrence. The pathological subtype of the patient who was operated twice for re-growth was secretory grade 1 meningioma in the first operation and her pathological subtype was reported as secretory/transitional grade 1 in the second operation. One of the transitional grade $1 \mathrm{OGM}$ patients had a synchronous frontal convexity meningioma of fibrous grade 1 subtype that was resected totally in the same session by the frontal approach.

\section{Treatment Outcomes}

In the follow-up period (median 64 months), the overall tumor control rate was $96.8 \%$. A total of 1 recurrence $(1.6 \%)$ and 1 re-growth (1.6\%) were detected. The median follow-up to recurrence/re-growth of these was 25.5 months (range, 23-28 months). The 2 patients (1 recurrent and 1 re-growth) were treated surgically. The recurrent tumor was an atypical (grade 2) meningioma. No re-growth was observed in 3 patients with STR and had Gamma Knife treatment in their follow-up.

The mean RFS was $66 \pm 38.2$ months (median RFS; 64 months, range; 1-239). Our number of recurrences/re-growths was small and a longer period of follow-up is needed to figure out a better RFS.

Among potential factors, GTR and WHO grade 1 were associated with longer RFS $(p<0.05)$ whereas age $(<50$ vs $\geq 50$ ), sex, preoperative KPS, tumor size $(<6 \mathrm{~cm}$. vs $\geq 6 \mathrm{~cm}$.), type of approach, presence of ethmoidal invasion, optic canal involvement, vascular encasement and hyperostosis had no prognostic value on RFS.

\section{DISCUSSION}

Francesco Durante performed the first successful resection of OGM in 1885 via a left frontal craniotomy (16). In 1938, Cushing and Eisenhardt described the surgical principles of the OGM resection in a series of 22 patients through a unilateral subfrontal approach (12). Although there are many publications concerning the treatment of OGMs in the literature, the optimal surgical approach to these tumors remains controversial. The pterional, frontal, bifrontal and their variations are the most common open transcranial procedures reported in case series of OGMs $(3,7,8,10,11,14,17-$ $19,23,25,28,29,33,34,36,37,39,40,43)$.

The pterional approach, described by Yaşargil, is commonly used for vascular and neoplastic lesions of the anterior and middle cranial fossa (42). Hassler first reported a series of 11 OGMs using the pterional approach in 1989 (19). This approach has several advantages. First, it allows earlier control and dissection of important neurovascular structures i.e. internal carotid artery, anterior cerebral artery (ACA), anterior communicating artery, optic nerve and chiasm from the posterior pole of the tumor while minimizing damage to the frontal lobes and the olfactory nerves. Early CSF release can be achieved by opening the basal cisterns before tumor dissection. It is less invasive and time consuming than bifrontal craniotomy and avoids CSF leak because the frontal sinus is not transected. Finally, the frontal veins are not compressed as the frontal lobes are not elevated, protecting the venous drainage during surgery $(13,19,30,34)$. The main disadvantage of this approach is a narrow working angle but contralateral parts of the tumor can be easily reached after falx resection $(10,19,36)$.

The unifrontal approach, described by the Olivecrona and Urban in 1935 (27) and Cushing and Eisenhardt in 1938 (12), is one of the most commonly utilized craniotomies for OGMs and has the advantage of sparing the contralateral frontal lobe and superior sagittal sinus $(36,39)$. It avoids bifrontal retraction and possible cognitive dysfunction $(5,6)$. The disadvantages of this technique are late exposure of neurovascular structures at a far distance from the site of the craniotomy and risk of CSF leak caused by opening of frontal sinuses. Moreover, when dissection requires frontal lobe elevation, there may be significant compression of the frontal bridging veins $(5,19,32,36)$. Kempe addressed the importance of early identification of the optic nerve and adjacent arteries and proposed a unifrontal craniotomy (20).

The current debate concerning the surgical strategy concentrates on the extent and safety of tumor resection and the optimal approach. The percentage of GTR of OGMs ranged from 50 to $100 \%$ in previous reports $(8,11,12,18,19,30,33,34,36,39)$. In recent microsurgical series, high rates of total tumor resection were achieved without a significant increase in morbidity $(19,26,30,40)$. The rate of GTR overall was $93.7 \%$ in our patients (pterional 100\%, unifrontal $84 \%$ ). When 20 large OGMs were taken into consideration, we observed that the tumor was totally removed in $85 \%$ of cases. In patients with large OGMs operated through the pterional and unifrontal approaches, total resection rates were $100 \%$ and $76.9 \%$ respectively. That is, there was no difference in total resection rates between the two approaches. Gazzeri et al. reported similar rates $(86.1 \%)$ in large OGMs via the bifrontal approach (18). Tomasello and d'Avella reported more than $90 \%$ total resection rates using the pterional approach $(13,38)$. 


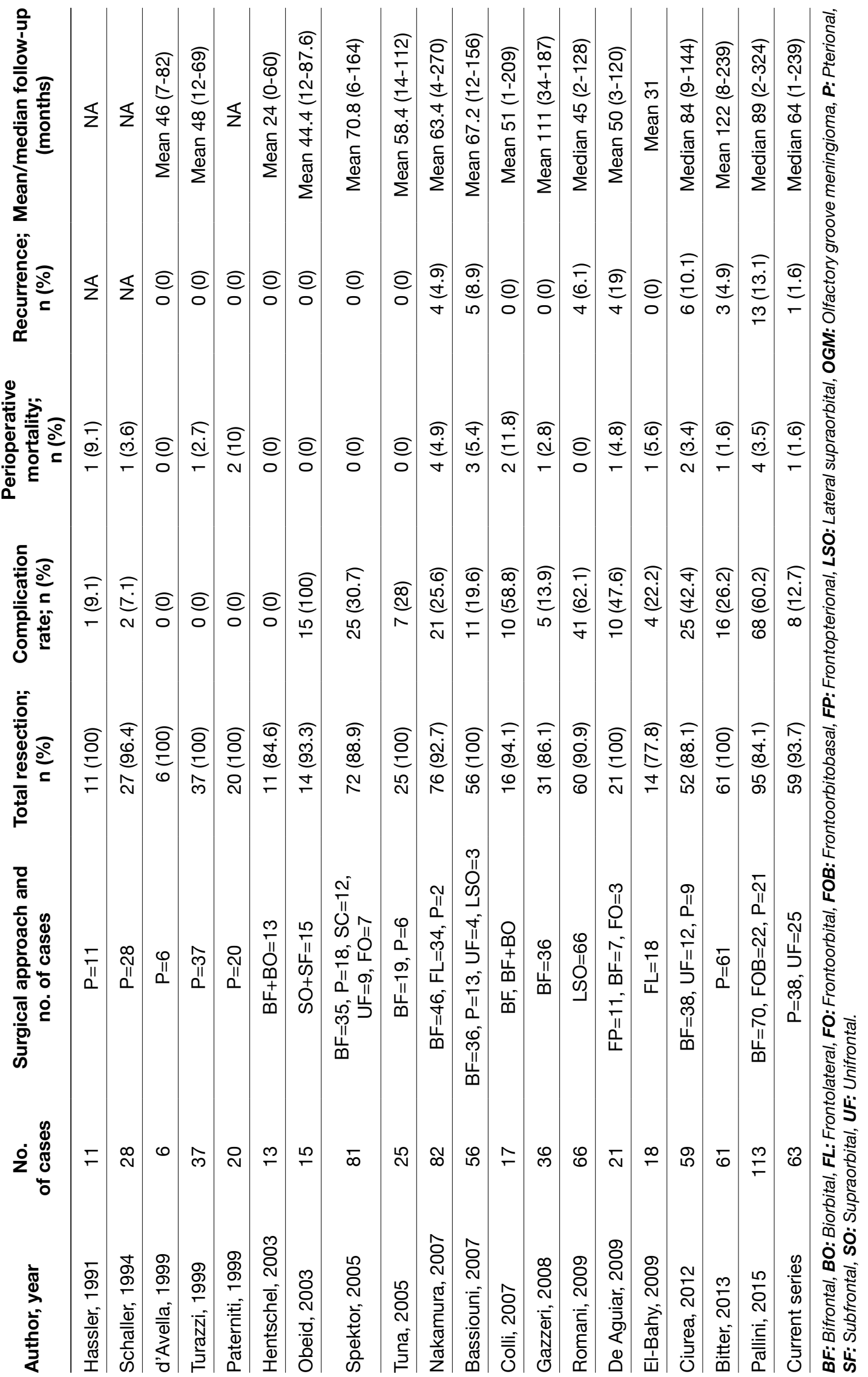


Extension into paranasal sinuses has been reported in 5 to $46 \%$ of patients with OGMs $(8,15,25,33,36,39)$. Ethmoidal invasion was evident in $29.5 \%$ of our patients and was associated with the size of the tumor $(p<0.05)$. Hyperostosis associated with meningioma is a result of tumor invasion rather than a reactive process (31). The frequency of hyperostosis reported in previous series ranged from 28.3 to $62 \%(21,25,28,33)$. In our series, the rate of hyperostosis was $73.8 \%$, occurring significantly more frequently in medium and large OGMs. The higher rate of hyperostosis in our series can be related to the high percentage $(82.0 \%)$ of medium and large tumors.

The frequency of optic chiasm and optic nerve involvement in series of OGMs was found to be $6.5-45.4 \%(7,8,21,25,33,36)$. In our patients, optic canal involvement was found in $9.8 \%$ of cases with a statistically significant association with the tumor diameter, consistent with the findings of Romani et al. who observed the larger the tumor the more often the optic apparatus involvement (33). Additionally, vascular encasement, mainly the ACA, was also reported in case series in up to $50 \%$ of patients $(7,21,28,33)$. Vascular encasement was seen in $8.2 \%$ of patients in our series. To the best of our knowledge, middle fossa extension was not reported in previous series. We have found that middle fossa extension was significantly associated with large tumor size and STR $(\mathrm{p}<0.05)$.

Postoperative complications include CSF leak, hematoma, epilepsy, retraction-related swelling, edema, neurological deficits, visual or mental deterioration and wound infections. The rate of life threatening complications ranges from 0 to $25.7 \%$, occurring more frequently with bifrontal approach $(3,8,18,28-30,33,34,36,39,40)$. Hematoma and contusion were the most common complications without a significant difference between the two approaches in our series.

The mortality rates for surgery of OGMs ranged from 0 to $10 \%$ in the last two decades $(25,28)$. Compared to earlier reports, these rates are considerably lower owing to advances in microsurgery $(12,35)$. A meta-analysis conducted by Pallini et al. demonstrated that mortality rates were higher when the bifrontal approach was used (28). Death related to surgery occurred in one patient $(1.6 \%)$ due to left MCA infarction operated via a right pterional approach. This rate is similar to the mortality rates reported by Spektor et al. and Bitter et al., $1.3 \%$ and $1.6 \%$ respectively $(8,36)$.

The extent of initial resection was demonstrated to be the most important factor in prevention of recurrence of meningiomas $(2,4,9,26,28)$. Additionally, paranasal sinus infiltration was associated with higher risk of recurrence $(25,33)$ and the risk was higher when involved bone was not removed $(8,15,26)$. The recurrence rates for $O G M s$ reported in the literature ranged from 0 to $41 \%$ in surgical series depending on the extent of the initial resection and duration of follow-up period ranging widely from 3.7 to 25 years $(3,5,7,8,18,25,26,33,36,40)$. Only surgical series with short durations of follow-up reported no recurrence $(26,40)$. Mirimanoff et al. reported $30 \%$ and $41 \%$ recurrence rates at 5 and 10 years after surgery (24). Tumor recurred in 1 patient (1.6\%) while 1 patient (1.6\%) showed re-growth in our cases. The median follow-up time was 64 months (1-239 months). Our series did not have enough number of cases with recurrence/re-growth to make a statistical analysis of the significance of the relation between the probable determinants like tumor size, WHO grade, approach, hyperostosis, ethmoidal invasion, middle fossa extension, optic canal involvement and vascular encasement. Table VI gives a summary of published OGM series.

\section{- CONCLUSION}

OGMs were removed using the pterional and unifrontal approach. Both surgical procedures proved to be safe and effective overall; therefore the decision of using aggressive approaches should be reasonable. The pterional approach achieved significantly higher rates of GTR and longer RFS, including large tumors with comparable complication rates. Ethmoidal invasion, middle fossa extension, optic canal involvement and vascular encasement were the major predictors of STR.

\section{- REFERENCES}

1. Adappa ND, Lee JYK, Chiu AG, Palmer JN: Olfactory groove meningioma. Otolaryngol Clin North Am 44:965-980, 2011

2. Adegbite AB, Khan MI, Paine KW, Tan LK: The recurrence of intracranial meningiomas after surgical treatment. J Neurosurg 58:51-56, 1983

3. de Aguiar PHP, Tahara A, Almeida AN, Simm R, Silva AN da, Maldaun MVC, Panagopoulos AT, Zicarelli CA, Silva PG: Olfactory groove meningiomas: Approaches and complications. J Clin Neurosci 16:1168-1173, 2009

4. Al-Mefty O, Holoubi A, Rifai A, Fox JL: Microsurgical removal of suprasellar meningiomas. Neurosurgery 16:364-372, 1985

5. Al-Mefty O: Tuberculum sella and olfactory groove meningiomas. In: Sekhar LN , Janecka IP (eds). Surgery of Cranial Base Tumors. New York: Raven Press, 1993:507-519

6. Babu R, Barton A, Kasoff SS: Resection of olfactory groove meningiomas: Technical note revisited. Surg Neurol 44:567572, 1995

7. Bassiouni H, Asgari S, Stolke D: Olfactory groove meningiomas: Functional outcome in a series treated microsurgically. Acta Neurochir (Wien) 149:109-121, 2006

8. Bitter AD, Stavrinou LC, Ntoulias G, Petridis AK, Dukagjin M, Scholz M, Hassler W: The role of the pterional approach in the surgical treatment of olfactory groove meningiomas: A 20year experience. J Neurol Surg B Skull Base 74:97-102, 2013

9. Black PM: Meningiomas. Neurosurgery 32:643-657, 1993

10. Ciurea AV, lencean SM, Rizea RE, Brehar FM: Olfactory groove meningiomas: A retrospective study on 59 surgical cases. Neurosurg Rev 35:195-202, 2012

11. Colli BO, Carlotti CG, Assirati JA, Santos MBM, Neder L, Santos AC, Batagini NC: Olfactory groove meningiomas: Surgical technique and follow-up review. Arq Neuropsiquiatr 65:795-799, 2007

12. Cushing $\mathrm{H}$, Eisenhardt $\mathrm{L}$ : The olfactory meningiomas with primary anosmia, in Meningiomas: Their Classification, Regional Behavior, Life History and Surgical End Results. Springfield IL: Charles C. Thomas, 1938:250-282 
13. d'Avella D, Salpietro FM, Alafaci C, Tomasello F: Giant olfactory meningiomas: The pterional approach and its relevance for minimizing surgical morbidity. Skull Base Surg 9:23-31, 1999

14. de Almeida JR, Carvalho F, Vaz Guimaraes Filho F, Kiehl TR, Koutourousiou M, Su S, Vescan AD, Witterick IJ, Zadeh G, Wang EW, Fernandez-Miranda JC, Gardner PA, Gentili $\mathrm{F}$, Snyderman $\mathrm{CH}$ : Comparison of endoscopic endonasal and bifrontal craniotomy approaches for olfactory groove meningiomas: A matched pair analysis of outcomes and frontal lobe changes on MRI. J Clin Neurosci 22:1733-1741, 2015

15. Derome PJ, Guiot G: Bone problems in meningiomas invading the base of the skull. Clin Neurosurg 25:435-451, 1978

16. Durante F: Estirpazione di un tumore endocranico. Arch Atti Soc Ital Chir 2:252-255, 1886 (In Italian)

17. El-Bahy K: Validity of the frontolateral approach as a minimally invasive corridor for olfactory groove meningiomas. Acta Neurochir (Wien) 151:1197-1205, 2009

18. Gazzeri R, Galarza M, Gazzeri G: Giant olfactory groove meningioma: Ophthalmological and cognitive outcome after bifrontal microsurgical approach. Acta Neurochir (Wien) 150:1117-1125, 2008

19. Hassler W, Zentner J: Pterional approach for surgical treatment of olfactory groove meningiomas. Neurosurgery 25:942-945, 1989

20. Kempe LG, VanderArk GD: Anterior communicating artery aneurysms. Gyrus rectus approach. Neurochirurgia (Stuttg) 14:63-70, 1971

21. Koutourousiou M, Fernandez-Miranda JC, Wang EW, Snyderman $\mathrm{CH}$, Gardner PA: Endoscopic endonasal surgery for olfactory groove meningiomas: Outcomes and limitations in 50 patients. Neurosurg Focus 37:E8, 2014

22. Lyons MK, Birch BD, Wilkens JA, Miller K: Long-term followup and clinico-histopathological features of Simpson grade 1 surgical resection of large olfactory groove meningioma. Open Neurosurg J 4:18-23, 2011

23. Mielke D, Mayfrank L, Psychogios MN, Rohde V: The anterior interhemispheric approach: A safe and effective approach to anterior skull base lesions. Acta Neurochir (Wien) 156:689696, 2014

24. Mirimanoff RO, Dosoretz DE, Linggood RM, Ojemann RG, Martuza RL: Meningioma: Analysis of recurrence and progression following neurosurgical resection. J Neurosurg 62:18-24, 1985

25. Nakamura M, Struck M, Roser F, Vorkapic P, Samii M: Olfactory groove meningiomas: Clinical outcome and recurrence rates after tumor removal through the frontolateral and bifrontal approach. Neurosurgery 60:844-852, 2007

26. Obeid F, Al-Mefty O: Recurrence of olfactory groove meningiomas. Neurosurgery 53:534-542, 2003

27. Olivecrona $\mathrm{H}$, Urban $\mathrm{H}$ : Über Meningeome der Siebbeinplatte. Brun's Beitr Klin Chir 161:224-253, 1935 (In German)

28. Pallini R, Fernandez E, Lauretti L, Doglietto F, D'Alessandris QG, Montano N, Capo G, Meglio M, Maira G: Olfactory groove meningioma: Report of 99 cases surgically treated at the Catholic University School of Medicine, Rome. World Neurosurg 83:219-231, 2015
29. Park HY, Seol HJ, Nam DH, Lee JI, Kong DS, Kim JH, Park $\mathrm{K}$ : Treatment outcomes after surgical resection of midline anterior skull base meningiomas at a single center. $\mathrm{J}$ Clin Neurosci 19:1654-1658, 2012

30. Paterniti S, Fiore P, Levita A, La Camera A, Cambria S: Basal meningiomas. A retrospective study of 139 surgical cases. J Neurosurg Sci 43:107-113, 1999

31. Pieper DR, Al-Mefty O, Hanada Y, Buechner D: Hyperostosis associated with meningioma of the cranial base: Secondary changes or tumor invasion. Neurosurgery 44:742-746, 1999

32. Rachinger W, Grau S, Tonn JC: Different microsurgical approaches to meningiomas of the anterior cranial base. Acta Neurochir (Wien) 152:931-939, 2010

33. Romani R, Lehecka M, Gaal E, Toninelli S, Celik O, Niemela M, Porras M, Jaaskelainen J, Hernesniemi J: Lateral supraorbital approach applied to olfactory groove meningiomas: Experience with 66 consecutive patients. Neurosurgery 65:39-52, 2009

34. Schaller C, Rohde V, Hassler W: Microsurgical removal of olfactory groove meningiomas via the pterional approach. Skull Base Surg 4:189-192, 1994

35. Solero CL, Giombini S, Morello G: Suprasellar and olfactory meningiomas. Report on a series of 153 personal cases. Acta Neurochir (Wien) 67:181-194, 1983

36. Spektor S, Valarezo J, Fliss DM, Gil Z, Cohen J, Goldman J, Umansky F: Olfactory groove meningiomas from neurosurgical and ear, nose, and throat perspectives: Approaches, techniques, and outcomes. Neurosurgery 57:268-280, 2005

37. Telera S, Carapella CM, Caroli F, Crispo F, Cristalli G, Raus L, Sperduti I, Pompili A: Supraorbital keyhole approach for removal of midline anterior cranial fossa meningiomas: $A$ series of 20 consecutive cases. Neurosurg Rev 35:67-83, 2012

38. Tomasello F, Angileri FF, Grasso G, Granata F, De Ponte FS, Alafaci C: Giant olfactory groove meningiomas: Extent of frontal lobes damage and long-term outcome after the pterional approach. World Neurosurg 76:311-317, 2011

39. Tuna $\mathrm{H}$, Bozkurt M, Ayten M, Erdogan A, Deda H: Olfactory groove meningiomas. J Clin Neurosci 12:664-668, 2005

40. Turazzi S, Cristofori L, Gambin R, Bricolo A: The pterional approach for the microsurgical removal of olfactory groove meningiomas. Neurosurgery 45:821-825, 1999

41. Welge-Luessen A, Temmel A, Quint C, Moll B, Wolf S, Hummel T: Olfactory function in patients with olfactory groove meningioma. J Neurol Neurosurg Psychiatry 70:218-221, 2001

42. Yaşargil MG: General Operative Techniques, in Microneurosurgery. Vol: 4. New York: Thieme-Stratton, 1984: 208-233

43. Zimmer LA, Theodosopoulos PV: Anterior skull base surgery: Open versus endoscopic. Curr Opin Otolaryngol Head Neck Surg 17:75-78, 2009 